\title{
Identifying and Classifying Benefits of Integrated Healthcare Systems Using an Actor-Oriented Approach
}

\author{
Vasiliki Mantzana and Marinos Themistocleous \\ Information Systems Evaluation and Integration Network Group (ISEing) \\ Department of Information Systems and Computing, Brunel University, Uxbridge, UK
}

The demands of health system are set to evolve based on patients needs and thus, healthcare managers and clinicians require decision making tools that will support them in providing better services to patients. Currently, the non-integrated nature of healthcare Information Systems (IS) is strongly associated with both a reduction in the outcome of care as well as the many medical errors that occur. Recent reports show that around 23,360 people per annum die in UK due to problems related to the medical errors and mainly caused by the nonintegrated nature of the healthcare information systems. Development of an integrated IT infrastructure across the healthcare sector will result in enhanced services provided to all actors and will protect and improve human lives. During the last years, much emphasis has been given on Enterprise Application Integration (EAI) technology to bridge together disparate and autonomous systems. EAI is underutilised in the healthcare sector, with many studies showing that resistance to change and lack of awareness are among the main reasons associated with this phenomenon. Although the benefits of EAI are well analysed in literature, there is a need to understand and explain these benefits in the area of healthcare. This is of high importance since it will be easier to address the resistance to change and speed up the adoption of EAI. This paper proposes an actor-oriented approach to identify, analyse and classify benefits associated with the application of EAI in healthcare. The authors introduce a novel taxonomy to classify the EAI benefits and combine the proposed actor-oriented approach with an existing classification for EAI benefits. In doing so, they enhance the level of analysis and allow researchers and managers to better realise the benefits derived from the use of EAI in healthcare.

Keywords: Enterprise Application Integration (EAI), healthcare information systems, actors

\section{Introduction}

Information Systems (IS) play an increasingly crucial role in the revolution that is taking place in the healthcare field. Since the 60's there has been an effort to improve the healthcare sector through the use of advanced Information and Communication Technologies (ICT) [17, 42]. The reason for this is that technological advancement in the area of information systems is a key issue in the improvement of quality and productivity of healthcare systems [44, 57]. In an attempt to improve the healthcare services, different types of IS have been implemented, such as laboratory, radiology, pharmacy, human resource management, administrative and managerial systems [43].

Nonetheless, efforts to modernise healthcare services have resulted in the development of disparate, incompatible and heterogeneous systems $[21,49]$. The non-integrated nature of healthcare systems is strongly associated with a reduction in the quality of the care delivered to patients and with medical errors that occur in the healthcare arena. Some examples of medical errors are the following: (a) hard copy films are constantly lost/unavailable or (b) information needed for diagnosing is often missing and (c) errors usually occur in prescribing, administering and dispensing drugs to patients [12].

These medical errors have been recognised as significant contributors to patient harm. Limitations of healthcare systems are related to the loss of 64 persons per day in UK (Khoumbati et al., 2003). Based on the findings of two different major studies in U.S. hospitals, medical errors kill at least 44,000, and perhaps as many as 98,000 people each year [31]. It has 
to be mentioned that even the lower estimation of the medical errors $(44,000)$ is higher than the annual mortality from motor vehicle accidents $(43,458)$, breast cancer $(42,297)$, or AIDS (16,516). According to Sutherland and Willem [48] medical errors are the fourth leading cause of death in the United States! According to Kohn and Corrigan [31], the most common types of preventable errors are technical errors $(44 \%)$, diagnosis $(17 \%)$, failure to prevent injury (12\%) and errors in the use of a drug $(10 \%)$. The percentage of technical errors is high, especially in technical surgical specialties such as vascular surgery, cardiac surgery, and neurosurgery. However, Leape et al., [32] illustrated that three out of four errors in care hospitals are caused by systems failure. These errors have been characterised in the same research as preventable and it has been stated that improved information systems could reduce the percentage of preventable errors in the healthcare sector.

Sutherland and Willem [48] reported that minimum levels of automation would reduce the percentage of human life loss by $50-80 \%$. In addition, through the use of automated systems, the deaths related to medication errors could be reduced from 106,000 to less than 25,000. It has also been reported that by moving from a paperbased system to a digital system, which will be coordinated and integrated, the cost of administrative tasks will be dramatically decreased from $\$ 90$ billion to $\$ 5$ billion or less. Moreover, when heterogeneous healthcare systems function together, $\$ 85$ billion a year will be saved [37].

However, the necessity for an information integrated environment, which will be cost effective, flexible and adaptive, has emerged, as in the healthcare sector changes are and will be constant. In 1998 the UK National Health Service (NHS) published a National Service Framework (NSF) for commissioning cancer services in UK, in which it was mentioned that the integration of cancer-related levels of care with each other and with non-cancer related services will provide a comprehensive cancer service [47]. To this end, Wanless [57] reported that development of a secure, flexible integrated IT infrastructure in healthcare that will provide effective links and good communications between different parts of the service and beyond, is of great importance. In support of this, Anyanwu et al., [5] suggested that there is a need to integrate the disparate, heterogeneous healthcare information systems to improve collaboration between different healthcare departments.

In an attempt to bridge these systems together, many healthcare organizations have adopted integrated technologies, standards and approaches such as EDI, HL7, CEN/TC251, Synex, Synapses. Although the integration efforts undertaken so far have provided significant benefits, they have not resulted in the development of an integrated IT infrastructure that efficiently automates and integrates healthcare processes and services $[6,8,28]$.

However, the need for developing an integrated IT infrastructure in healthcare sector can be facilitated through the use of Enterprise Application Integration (EAI). EAI is a new generation of integration software, which has been used to integrate systems at both enterprise and crossenterprise level. Many private and public organizations have deployed EAI solutions [23, 53, $54]$ with the healthcare sector having recently realised the effectiveness and the functionality of EAI and have turned to its adoption [27].

Nevertheless, this is a new research area with many issues under research. In this paper, the authors focus on the benefits that derive from the application of EAI, as these have not been perceived as anticipated yet. In doing so, the authors follow a novel approach to classify the benefits associated with the application of EAI in healthcare. The paper proposes that an actororiented approach can be used to categorise the EAI benefits. Such, an approach allows a better realisation of the benefits and supports the decision making process as the EAI benefits are becoming clearer for each category of actors. Thus, the paper contributes to the body of knowledge and opens new avenues for research in this area.

\section{Enterprise Application Integration}

Enterprise Application Integration combines a variety of integration technologies such as message brokers and application servers, to build a centralised integration infrastructure [34]. As a result, it incorporates functionality from a diversity of systems and leads to the development 
of flexible and maintainable integrated IT infrastructures. There is, therefore, an increasing demand from private and public organizations to deploy EAI solutions and achieve intra and inter-organizational integration. All types (e.g. custom, e-business) and all combinations of information systems (e.g. custom-to-packagedto-e-business) can be pieced together using EAI with Themistocleous et al., [54] classifying all possible combinations of systems being integrated.

At a technical level, Themistocleous [50] empirically validated that integration is achieved through four layers namely: (a) Connectivity, (b) Transportation, (c) Transformation and (d) Process automation. The first layer creates points of access between the applications and the EAI infrastructure. The second one transfers the application elements (e.g. data, objects) among EAI infrastructure and applications. The Transformation layer translates and reformats the application elements into a recognisable format for the target(s) systems. The last layer is responsible for business process automation and integration. Depending on the requests and information it receives, it triggers all appropriate applications or tasks to integrate a business process.

From a business perspective, EAI results in the reduction of overall integration cost due to the decrement of both integration time and maintenance costs [45]. Also, EAI achieves Return On Investment (ROI) as it provides a flexible, manageable and maintainable IT infrastructure that supports the changing business and technical requirements. Based on an integrated enterprise architecture, organizations can increase their productivity, provide better services and improve the relationships with their collaborators [46]. Moreover, organizations can improve their performance [56]. Likewise, EAI supports strengthened supply chains and improved relationships and collaboration between organizations and suppliers. Other benefits include provision of a centralised point of control, reduction of skills level required to integrate applications, faster time to marketing and increased market share.

Organizations consider various factors when adopting Enterprise Application Integration. Themistocleous [51] and Themistocleous and Irani $[38,50]$ have studied the adoption of EAI in multinational organizations, proposed and validated a model that explains these influential factors. The proposed model includes factors such as: (a) costs, (b) barriers, (c) benefits, (d) internal pressures, (e) external pressures, (f) IT infrastructure, (g) IT sophistication, (h) support, (i) the existence of a framework for the evaluation of integration technologies and, (j) a framework for the assessment of EAI packages. This model has been adapted in the area of healthcare by Khoumbati et al., [27], who suggested that other factors like medical (medical decision-making) should be considered during the EAI adoption in healthcare.

According to Themistocleous et al., [54] barriers like (a) culture, (b) politics, (c) lack of knowledge or awareness and (d) resistance to change should be considered and are addressed when deploying EAI solutions, because they increase the risk and obstruct the adoption of EAI. Especially in the area of healthcare, these parameters are of high importance. For instance, the UK government has recently invested $£ 2.3$ billion to improve the healthcare information systems [57] with the aforementioned parameters, causing delays and putting the whole project at risk $[11,19]$. To this end, the authors suggest that a better awareness and communication between the various actors and management will significantly reduce these barriers (e.g. level of resistance to change) and therefore contribute the adoption of EAI. Among the rest, attention should be paid to the benefits realisation, since various healthcare actors can better understand real benefits associated with EAI and thus resist less.

\section{Classification of EAI Benefits in the Healthcare Sector}

The EAI benefits have been well identified, analysed and classified by Themistocleous and Irani [52] into (a) organizational, (b) managerial, (c) operational, (d) strategic and, (e) technical. Although, such taxonomy allows organizations to understand the benefits and manage them in groups, it does not provide the flexibility needed when analysing and explaining these benefits to the different actors. There is, therefore, a need for (a) identification of the benefits that are related to the adoption of EAI in healthcare and (b) classification of these benefits in 
a way that allows actors to better realise them. In addressing this void, this section identifies the benefits that derive from the application of EAI technology in healthcare sector, whereas section 4 proposes an actor-oriented approach for the categorisation of these benefits.

Much of the research conducted by Themistocleous and Irani [52] and Themistocleous [50]

\begin{tabular}{|c|c|c|}
\hline Dimension & Benefits & References \\
\hline Operational & $\begin{array}{ll}\text { - } & \text { Increases productivity } \\
\text { - } & \text { Reduces cost } \\
\text { - } & \text { Improves data quality } \\
\text { - } & \text { Improves data sharing/flow } \\
\text { - } & \text { Provides better access to data } \\
\text { - } & \text { Improves data presentation } \\
\text { - } & \text { Reduces medical errors } \\
\text { - } & \text { Achieves satisfaction } \\
\end{array}$ & $\begin{array}{l}\text { - } \text { Duke et al., [14] } \\
\text { - Linthicum [34] } \\
\text { - } \text { Ring and Ward-Dutton [45] } \\
\text { - } \text { James [24] } \\
\text { - } \text { Lubinski and Barr [37] } \\
\text { - James [24] } \\
\text { - } \text { Ginneken [5] } \\
\text { - Kalakota and Robinson [26] }\end{array}$ \\
\hline Managerial & $\begin{array}{ll}\text { - } & \text { Improves managerial control } \\
\text { - } & \text { Provides more understanding and control } \\
\text { - } & \text { Suppocesses } \\
\text { - } & \text { Improves allocation of resources } \\
\text { - } & \text { Improves quality of care provided } \\
\text { - } \quad \text { Improves work efficiency } \\
\text { - } \quad \text { Increases performance } \\
\text { - } \quad \text { Achieves return on investment } \\
\end{array}$ & $\begin{array}{ll}\text { - } & \text { Chwelos et al., [10] } \\
\text { - } & \text { Duke et al., [14] } \\
\text { - } & \text { Edwards and Newing [15] } \\
\text { - } & \text { James [24] } \\
\text { - } & \text { Ceusters et al., [9] } \\
\text { - } & \text { Linthinicum } \text { et al., [59] } \\
\text { - } & \text { Edwards and Newing [15] } \\
\end{array}$ \\
\hline Strategic & 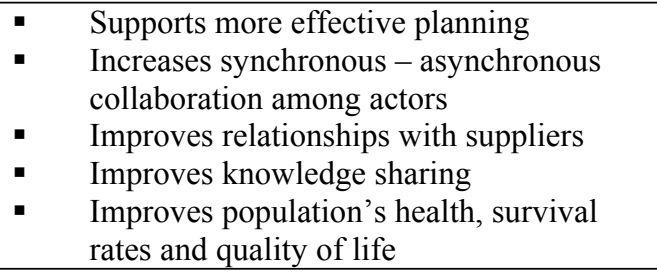 & $\begin{array}{l}\text { - } \text { James [24] } \\
\text { - } \text { Edwards and Newing [15] } \\
\text { - } \text { James al., [46] } \\
\text { - } \quad \text { Missi et al., [41] }\end{array}$ \\
\hline IT Infrastructure & $\begin{array}{ll}\text { - } & \text { Reusability of objects } \\
\text { - } & \text { Reduces development risk } \\
\text { - } & \text { Support the use of e-healthcare and } \\
\text { telemedicine-based patient support } & \text { models } \\
\text { - } & \text { Achieves non-invasive solutions } \\
\text { - } & \text { Achieves process integration } \\
\text { - } & \text { Provides objects/components integration } \\
\text { - } & \text { Provides data integration } \\
\text { - } & \text { Integides real-time integration } \\
\text { - } & \text { Integrates packaged systems } \\
\text { - } & \text { Integrates e-business solutions }\end{array}$ & $\begin{array}{ll}\text { - } & \text { Altmann et al., [1] } \\
\text { - } & \text { Jartinez and Redondo [39] } \\
\text { - } & \text { Ring and Ward-Dutton [45] } \\
\text { - } & \text { Ring and Ward-Dutton [45] } \\
\text { - } & \text { Linthicum [36] } \\
\text { - } & \text { Zahavi [58] } \\
\text { - } & \text { Themistocleous and Irani,[52] } \\
\text { - } & \text { Klasell and Dudgeon [30] } \\
\text { - } & \text { Ring and Ward-Dutton [45] } \\
\text { - } & \text { Themistocleous et al., [55] }\end{array}$ \\
\hline Organizational & $\begin{array}{ll}\text { - } & \text { Reduces hospitalisation } \\
\text { - } & \text { Reduces waiting times } \\
\text { - } & \text { Reduces cancelled operations } \\
\text { - } & \text { Achieves effective clinical } \\
& \text { administrative management } \\
\text { - } & \text { Increases business efficiency } \\
\text { - } & \text { Supports clinical decision making } \\
\text { - } & \text { Results in reliable data } \\
\text { - } & \text { Increases data analysis } \\
\text { Reduces paper work processes }\end{array}$ & $\begin{array}{ll}\text { - } & \text { Ginneken [5] } \\
\text { - } & \text { Godefridus et al., [20] } \\
\text { - } & \text { Godefridus et al., [20] } \\
\text { - } & \text { Zhanjun et al., [59] } \\
\text { - } & \text { James [24] } \\
\text { - } & \text { Zahavi [58] } \\
\text { - } & \text { Klasell and Dudgeon [30] } \\
\text { Martinez and Redondo [39] }\end{array}$ \\
\hline
\end{tabular}

Table 1. Proposition of EAI Benefits for Healthcare Sector. 
focuses on the realisation and classification of EAI benefits associated with EAI adoption in multinational enterprises. Some of the benefits identified by the aforementioned authors are specific for private companies and it is difficult to apply them to the area of healthcare (e.g. competitive advantage). However, there is a wide range of benefits identified by Themistocleous and Irani [52] and Themistocleous [50] that are generic EAI benefits and can also apply in the case of healthcare. For instance, Themistocleous and Irani [52] supported and validated that EAI can integrate all types of systems (e.g. legacy, packaged and e-business). This benefit can be achieved in any application of EAI technology and in any environment (e.g. healthcare, private or public sector).

An attempt to understand the benefits from the use of integration technologies such as Health Level 7 (HL7) and EDI in healthcare has been reported by Khoumbati et al., [28] and include, among others, the following:

- Reduce medical errors

- Reduce operational cost

- Reduce paperwork processes

- Improve quality of patients' care

- Improve work efficiency

- Improve managerial control

- Increase patients' satisfaction

- Increase collaboration among hospitals

- Improve decision support

- Achieve effective clinical and administrative management

- Reduce hospitalization

The authors propose that these benefits might also be achieved in case of EAI application in healthcare. The literature provides evidences that justify this argument as EAI supports a more advanced and detailed level of integration than the technologies used to integrate healthcare information systems (e.g. EDI, HL7, CEN/TC251, Synex, Synapses etc) [29]. To this end, the authors reviewed benefits proposed by Themistocleous and Irani [52] and Khoumbati et al., [28] and adapted them in the area of healthcare. In doing so, they summarised them in Table 1 and will test them through the case study presented in section 6 . This work is novel, it is one of the first attempts in this area and it contributes to the improvements accomplished in the field of healthcare systems integration.

\section{Healthcare Actors}

Flower [18] describes healthcare organizations as ongoing series of interrelationships. These interrelationships happen between patients and their families, doctors, institutions, pharmacies, vendors, technicians, public health network, and the whole world of knowledge, data and information about health, disease, medicine and prevention. The scope of health sector is to help all of those connections to become closer, more intimate, deeper, wider and more easily navigated. The IT revolution will not only offer ways to deliver health care more widely and more efficiently than today, but it will also change the relationship between health services and the people who use them. Thus, the actors' needs and requirements, as well as the impact of the adopted technology on them, should be studied and taken into consideration. Similarly, adoption of the EAI technology will affect not only the way the practice of medicine is applied, but also the healthcare system actors and the interrelationships between them. It is, therefore, of great importance to study the benefits deriving from the EAI adoption, and to identify how each of the healthcare actors will be benefited by EAI implementation.

For the purpose of this research, the authors are focusing on an actor-oriented approach to identify, classify and analyse the EAI benefits. The authors use the term actor to refer to all human and non human users that interact with the healthcare system. This is not the first time that an actor-oriented approach is employed for the classification of the benefits that are derived from the adoption of an innovative technology in the healthcare area. In 1993, the National Health Service published a report, in which this approach was used to classify benefits of the Electronic Health Care Records (EHCR). This report identified three different "worlds" that would be affected by the use of EHCR: the 


\begin{tabular}{|c|c|c|c|c|c|}
\hline & \multicolumn{4}{|c|}{ ACTORS } \\
\hline & & Acceptor & Provider & Supporter & Controller \\
\hline $\begin{array}{l}\text { D } \\
\text { I } \\
\text { M }\end{array}$ & Human (H) & $\begin{array}{l}\text { 1. Patients } \\
\text { 2. Next of kin }\end{array}$ & $\begin{array}{l}\text { 3. Clinicians } \\
\text { 4. Non-clinicians } \\
\text { 5. Clinical students }\end{array}$ & $\begin{array}{l}\text { 8. Administrators } \\
\text { 9. Legal professionals } \\
\text { 10. Researchers }\end{array}$ & 14. Managers \\
\hline $\begin{array}{l}\mathbf{E} \\
\mathbf{N} \\
\mathbf{S} \\
\mathbf{I} \\
\mathbf{O} \\
\mathbf{N}\end{array}$ & $\begin{array}{c}\text { Organizational } \\
\text { (O) }\end{array}$ & - & $\begin{array}{l}\text { 6. Hospitals } \\
\text { 7. Medical departments } \\
\text { - Clinics }\end{array}$ & $\begin{array}{l}\text { 11. Suppliers } \\
\text { 12. Technologists } \\
\text { 13. Insurance companies }\end{array}$ & $\begin{array}{l}\text { 15. Government (e.g. } \\
\text { Department of } \\
\text { Health, Economics) } \\
\text { 16. Health authorities }\end{array}$ \\
\hline
\end{tabular}

Table 2. Taxonomy of Healthcare Actors.

(a) patients' world (patients, next of kin, carers), (b) the clinicians' world (clinicians, nonclinicians, responsible clinician, a health care facility and clinical students) and (c) the third parties world (controller, technologist, administrator, legal professional, other third parties) [2]. Similarly, Broshy et al., [7] anticipated that ICT would result in interrelated changes in healthcare such as: (a) more activist patients, (b) better-informed care providers and (c) more efficient healthcare administration. Clearly, both approaches focus on common actors like (a) acceptors (e.g. patients), (b) providers and (c) supporters.

In this paper, alike, the authors extend the approaches presented above to classify the benefits that will be obtained by the adoption of the EAI technology in the healthcare sector. In doing so, they propose that the actors can be classified in four categories instead of three, namely: (a) providers, (b) acceptors, (c) supporters and (d) controllers. Controllers were considered as an independent category of actors, as their role in healthcare differs a lot from the supporters (e.g. technologists, administrators). Also, the authors suggest that in each of the four proposed categories there are actors that can be classified in two different dimensions: (a) human and (b) organizational. The implications of this categorisation are that: (a) it improves the level and the depth of analysis (more detailed), (b) it can further facilitate the decision making process and (c) it separates human actors from the organizational ones and it, therefore, allows different strategies to be applied when focusing on one or on the other dimension. The latter is in accordance with other classifications published in literature, which separate human and organizational parameters [22]. The proposed taxonomy for the actors is presented in Table 2.

\section{Research Methodology}

An interpretative, qualitative multiple case study strategy was selected to conduct this research. Interpretativism stance was adopted, as the aim of this paper is to identify and understand the benefits related to EAI implementations in healthcare. An interpretativism stance allows the authors to navigate and better explain this phenomenon in the organizational setting. Also, the authors suggest that in the context of this research a qualitative approach is more appropriate, as such approach can be used to: (a) investigate little-known phenomena like understanding and analysing EAI benefits; (b) examine in depth complex processes (EAI decisionmaking); (c) examine the phenomenon in its natural setting and, (d) learn from practice. A multiple case study strategy was employed to explore and understand the benefits associated with EAI adoption. In doing so, various data collection methods, such as interviews, documentation, and observation, were used. The bias that is considered to be a danger in using qualitative research approach was overcome in this research through data triangulation. The use of multiple data collection methods makes the triangulation possible, which provides stronger substantiation of theory [16]. For 
the purpose of this paper, three types of triangulation were used: (a) data [13]; (b) methodological and, (c) interdisciplinary triangulation [25].

\section{Case Data}

Due to confidentiality reasons, the name of the hospital that has been studied cannot be published, so the authors will use the name HOSP_EAI to refer to this organization. HOSP_EAI is a specialized acute (specialist) trust, a major international centre for postgraduate teaching and research run in UK. It has more than 1,200 employees who work on 11 sites. This specialized NHS Foundation Trust consists of nine clinical departments, which cannot be named due to confidentiality reasons. HOSP_EAI organizational chart consists of four divisions. Every employee, each service and department, belongs to one of four divisions, each of which has a separate management. The management team consists of the Chief Executive Officer (CEO), who heads the HOSP_EAI and eight departmental directors (Director of Finance, Director of Nursing and Development, Medical Director, Director of Research and Development, Director of Corporate Governance, Director of Education, Director of Personnel and Director of Planning and Performance).

By 1997, with the support of the Commission for Health Improvement (CHI), the hospital decided that significant improvements had to be made to the HOSP_EAI, as they were facing many problems including:

- Lack of integration of primary, secondary and tertiary services.

- Lack of communication between the trust and its patients, from admission to discharge.

- Lack of integration of research and development with audit and learning as a continuous process.

- Unsatisfactory quality level of patient services and care.

- Development of a patient centric approach to support involving patients in the medical decision making process and keeping them informed on issues like delays, admissions, and their treatment.

- Need to keep health professionals up to date informed in their practices and to have them properly supervised, where necessary.

- Need to introduce telemedicine and e-Health applications.

- Need to reduce the errors and adverse events, as well as to learn from mistakes and share that learning with others.

- Lengthy patient waiting times and need for a booking system.

However, the UK healthcare sector modernisation effort has been one of the main driving forces for changing the information system at HOSP_EAI. During recent years, the UK government, through the UK National Health Service (NHS) Care plan, has focused on the development of an essential patient centric information system, to provide, efficiently and effectively, care within an integrated infrastructure between health and social care [4]. In UK, the NHS has implemented a new approach to the effective and efficient management of its information resources. According to this approach, known as the HORUS model, the information in the healthcare sector should be [33]:

- Held securely and confidentially.

- Obtained fairly and efficiently.

- Recorded accurately and reliably.

- Used effectively and ethically.

- Shared lawfully and appropriately.

The key objectives for the UK Government Health Sector, within the National Health Service, in this era are to provide high quality care to patients, twenty four hours a day, seven days a week $(24 / 7)$ and to modernise healthcare services, especially through the new Information Systems Strategy, Information for Health (1998 $-2005)[3]$.

HOSP_EAI decided to seek more efficient solutions for their IT infrastructure, due to (a) the problems that the hospital faced and (b) the targets set by the NHS. Therefore, HOSP_EAI developed partnerships with a small number of software suppliers to redevelop and integrate the existing systems. The hospital turned to 
consultants and suppliers to provide software packages that match precisely with its business processes. This practise is in accordance with published literature which suggests that organizations seek support from consultants and other experts to evaluate and adopt EAI solutions [51]. The consultants initiated the development of a pilot project to support integrated IT infrastructure. This was supposed to integrate a number of processes of the HOSP_EAI. In doing so, the hospital managed to assess the benefits of EAI technology and make decisions for further development. These actions (pilot system and benefits evaluation) are also in accordance with existing practices practised by organizations in other sectors, when deploying EAI applications.

Based on the evaluation results, HOSP_EAI revisited its plans and decided to integrate the $\mathrm{Pa}$ tient Administration System (PAS) that holds all patient demographics (e.g. address, date of birth, GP, admission details) with existing administrative and clinical systems. In addition to this, HOSP_EAI is planning to integrate its telemedicine and e-health systems with the EAI application.

The authors interviewed different categories of actors listed in Table 2, to identify the benefits that each actor gained after the adoption of the pilot EAI system in this hospital. After interviewing the above-mentioned actors, the authors realised that the benefits of integration were considerable. Some of these benefits are summarised below:

- There has been no need to go through the lengthy and extremely expensive procurement process as the software vendor invested in this project (development of customised adapters for healthcare systems) and expects benefits from the application of this solution to other hospitals.

- Users report improvement in the systems performance (high-speed performance and increased scalability).

- Real cost savings of around $£ 30,000$ per year have been achieved, which resulted in returned investment (the implementation cost was $\mathfrak{£} 40,000)$.

- Specialist knowledge and advice is being shared more efficiently between specialists of the Trust and specialists from different hospitals. Furthermore, the Trust, through the adoption of the EAI technology, has managed to reduce patients' waiting times and to improve satisfaction of all the actors involved in the Trust. It has been reported that waiting times for both outpatient appointments and surgery have been steadily reduced and that targets in the NHS plan have been exceeded. The latter is an important finding since this is the first time to be reported.

- The EAI application supports and enhances the functionality of telemedicine and e-health applications. This is another interesting finding which demonstrates that the use of EAI can extend the use of other advanced technologies in healthcare, thus offering a high quality system to be used by healthcare as a critical tool.

All these benefits have been categorised and presented in Table 3, by using a combination of (a) categorisation of the EAI benefits as presented in Table 1 and (b) taxonomy of the healthcare actors as presented in Table 2. The authors combined the two taxonomies presented in Tables 1 and 2, as they suggest that such a combination can provide a more detailed level of analysis. Horizontally, Table 3 illustrates EAI benefits grouped in five categories (operational, managerial, strategic, IT infrastructure and organizational). Vertically the healthcare actors are illustrated grouped into acceptors, providers, supporters and controllers. Each of these categories is broken down into human and organizational sub-actors. Due to space limitations, the authors refer to each of the actors using the corresponding number given to them in Table 2. For instance, the actor number 1 refers to the patient, whereas the actor number 16 refers to health authorities.

Ranking of the benefits follows a low (o) medium $(\bullet)$, high $(\bullet)$, scale of ranking, similar to the scale used by Miles and Huberman [40]. In addition, two other symbols are used for ranking. The symbol (-) indicates that there is no available information whereas the symbol $(\mathbf{x})$ codes that a benefit has no impact on a specific actor. 


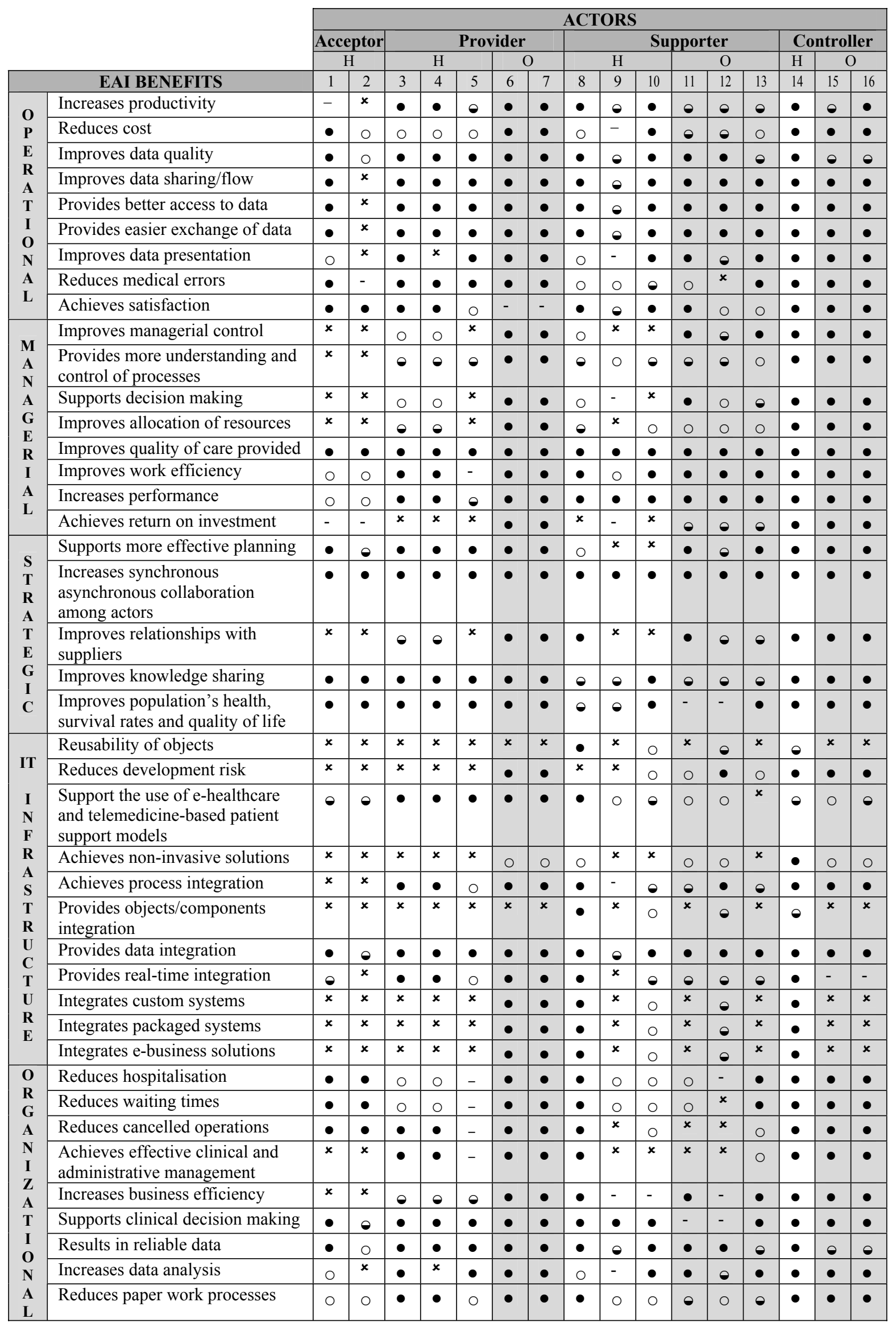

Table 3. EAI Benefits in Healthcare Classified by Actors. 


\section{Data Analysis}

This section discusses and analyses the main findings of the case study presented in Table 3 and summarised below.

Operational EAI Benefits: From the findings it appears that the actor Next of Kin is lowly benefited in case of reduced cost and improved data quality and highly in the satisfaction achieved. In the remaining six benefits of this category, this actor has no benefit. Another actor that is partially benefited is the Legal Professional whose level of benefit is not similar to the rest actors. For instance, seven of the nine benefits in this category are reported. Its level of benefit is much higher than the Next of Kin's, but lower than that of other actors. The remaining (14) actors are highly benefited from this category of benefits and they reported almost the same level of satisfaction. However, there are differences in one or two benefits. For example, the reduce cost benefit, appears to be of low importance for Next of Kin, Clinicians, non-Clinicians, Medical Students, and Administrator, whereas it is of high importance for the remaining actors, except for Legal Professional who did not report any level of benefit.

Managerial EAI Benefits: There are evidences from Table 3 depicting that the organizational dimension of actors (e.g. Hospitals, Government) is more benefited comparing to the human actors (e.g. Patients, Doctors). Also, it is revealed that the organizational dimension of Providers and Controllers has exactly the same level of benefit in this category (Managerial EAI benefits). In addition, among human actors, only the Managers have the same level of satisfaction with the organizational dimension of the two aforementioned categories of actors. Other human actors such as Patients, Next of Kin, Medical Students, Legal Professionals and Researchers, have similar level of benefit for this category of EAI benefits. For instance, all these actors have no benefit in case of improved managerial control or the support of decisionmaking process by EAI. This implies that, when introducing the idea of developing an EAI application, these benefits should not be reported to these actors, as they have no benefit. An observation should be made about the fact that EAI improves quality of care provided with all actors reporting high benefit. This indicates that the application of EAI in healthcare sector is of the benefit for all actors, not a specific one. Thus, much emphasis should be placed on this finding to reduce resistance to change associated with EAI adoption.

Strategic EAI Benefits: Similarly to the findings of the previous category (Managerial), it appears that the Controllers and the Organizational dimension of Providers are highly benefited from this category. It is suggested to emphasise the strategic benefits when approaching these actors (hospitals, managers, government, and health authorities), since all of them are involved in the decision making process. Another important finding is that EAI increases synchronous-asynchronous collaboration among actors and it is reported to be of high importance for all them. To this end, the authors suggest to explore this dimension in the future, since much work in the area of healthcare is based on the actors' interrelationships and, consequently, on the clinical pathways. Since EAI reduces the complexity, automates and integrates the business processes, it can be assumed that EAI reduces the interrelationships among actors. Such a research hypothesis should be tested in the future, as it is important for the healthcare to reduce the complexity of the interrelationships.

However, it has to be stated that the actors are highly satisfied not only by the improvements in synchronous - asynchronous communication between them, but also by (a) the increment in data integration, (b) the data sharing (c) the improvement in exchange of data, (d) the quality of data and (e) the quality of care provided to them. The whole picture acquired on the basis of this observation is that adoption of the EAI will improve the quality of care provided, by providing an improved synchronous - asynchronous collaboration among actors. Moreover, this communication will be characterised by the data that will be of high quality, integrated, shared and exchanged.

IT Infrastructure EAI Benefits: There are evidences from Table 3 depicting that the human dimension of the Controllers (Managers), the Administrators and the Organizational dimension of the Providers (Hospitals, Medical departments - Clinics) are highly benefited. The rest of the actors are not so highly benefited by the IT Infrastructure benefits that the EAI 
provides. To this end, it is suggested not to focus on the technical benefits when introducing the concept of EAI applications to these actors (e.g. Patient). Moreover, it has been observed that the majority of the actors perceive the data integration provided by the adoption of the EAI technology as a benefit involved in the healthcare.

Organizational EAI Benefits: The Controllers, the Administrators and the Organizational dimension of the Providers appear to be highly benefited from organization EAI benefits. Another interesting finding is that the Patients, the Next of Kin and the Insurance companies reported being highly benefited from the reduced hospitalization and the reduced waiting time, whereas clinicians and non-clinicians reported low benefits. In this case, it appears that an EAI solution will achieve more important benefits for the patients' world than the clinicians. This also indicates that an EAI solution is possibly more patient centric which is in accordance with the healthcare plans for developing an integrated patient centric system [57]. Thus, healthcare authorities should turn to EAI technology to meet their goals for patient centric systems.

\section{Conclusions}

This paper has highlighted the importance of improving the services provided by the healthcare sector through the integration of its information systems. Much work in this area has been done through the implementation of EAI applications. EAI is an emerging research area, but its application in the field of healthcare is underutilised. There are many reasons for this, including, among others, lack of awareness, politic issues and resistance to change. Many studies have indicated that the benefits realisation is a factor influencing the decision making process for EAI adoption.

In this paper the authors suggested that an actororiented approach could be used to identify, categorise and analyse the benefits deriving from the use of EAI in healthcare. It is important to focus on such an approach since there are many actors involved in this significant area and they have many different interests. Thus, it is essential to explain to each category of actors the benefits that this actor will perceive by the deployment of an EAI solution. In doing so, the benefits are becoming much clearer and customised to the actors' requirements. Consequently, it is suggested that it will reduce the resistance to change and speed up the adoption of EAI. Therefore, less people will be harmed from the non-integrated nature of healthcare IS.

The proposed taxonomy is novel in terms that it combinies an existing classification of EAI benefits with a new approach and it is applied in an area which lacks research and EAI implementation. Moreover, the paper makes novel contribution to the area as:

- This is one of the first attempts (if not the first) to identify, analyse and classify EAI benefits in healthcare sector.

- It is the first time that an actor-oriented approach is used to analyse and understand EAI benefits (in general).

- It is the first time that an actor-oriented approach is combined with an existing classification of EAI benefits. In doing so, the authors proved that the proposed combined classification improves the understanding and the analysis of EAI benefits. Hence, they suggest that a combination of the two classifications can be used in other sectors as well. However, to apply this combination in other areas, the actors (of the sector under investigation) should be first understood and identified.

The outcomes of this research presented herein are based on a real life case study. This is one of the limitations of this work, as the data and the observations derived from this case cannot be generalised. Nonetheless, it is not the intention of this paper to offer prescriptive guidelines to EAI benefits realisation in healthcare, but rather to describe a case study perspective that allows others to relate their experiences to those reported. Thus, this paper offers a broader understanding of the phenomenon of EAI realisation in the area of healthcare.

From the analysis presented in section 7 , it is observed that there are differences in the perception of EAI benefits from different categories of actors. Also, there are differences between diverse dimensions of actors within the same category. For instance the IT infrastructure benefits 
related to the dimensions human and organizational of Provider (category of actors) differ. This indicates that these different dimensions of the same category of actors should be approached in a different way when discussing the introduction of EAI technology. Also, this applies to diverse categories of actors. Another significant observation is that although benefits percieved by the patients are less in number comparing to other actors, they are ([benefits]) more important. This indicates that the benefits that derive for the patients are more qualitative in nature. As a result, it can be noted that an EAI solution can lead towards integrated systems that support the needs of patients more (patients' centric systems). It is also worth noting that this is a focal point for NHS, as it is aiming to the creation of integrated patients' centric systems.

Last but not least, the analysis suggests that there is a need for a more detailed categorisation of the actors. For instance, in the proposed taxonomy the actor Manager (in the category controller) represents all managers at all levels. However, this is not accurate in terms of analysis, as diverse categories of managers have different interests (e.g. IT Manager, Clinical manager, and Finance manager). For this reason, the authors suggest to expand this research in the future, to define the whole range of actors at all levels and then test again their perceptions regarding EAI benefits.

\section{References}

[1] Altmann, U., XML-based application interface services-a method to enhance interchange ability of disease specific systems, International Journal of Medical Informatics (2002), 68(1-3): pp. 27-37.

[2] AnONYMous, The Good European Health Record: Ethical and Legal Requirements, N.H. Service, Editor, 1993, London.

[3] ANONYMOUS, Information for Health - An Information Strategy for the Modern NHS 1998-2005: A National Strategy for Local Implementation, 2004.

[4] AnOnymous, The NHS Plan - A Plan for Investment, a Plan for Reform, 2004.

[5] Anyanwu, K., ET AL., Hlathcare Enterprise Process Development and Integration, 2002, University of Georgia, Computer Science Department, Georgia.
[6] Bernd, B. AND M. HolenA, Comparing middleware concepts for advanced healthcare architectures, International Journal of Medical Informatics (1997), 46(2): pp. 69-85.

[7] Broshy, E., ET AL., Managing for a Wired Health Care Industry, B.C. Group, Editor, 1998, UK.

[8] CARr, C. AND S. MoOre, IHE: A Model for Driving Adoption of Standards, Computerized Medical Imaging and Graphics (2003), 27(2-3): pp. 137146.

[9] Ceusters, W., ET AL., TSMI: a CEN/TC251 Standard for Time Specific Problems in Healthcare Informatics and Telematrics, International Journal of Medical Informatics (1997), 46(2): pp. 87-101.

[10] Chwelos, P., The Adoption and Impact of Electronic Data Interchange: A Test Internal and External Factors, in International Conference on Information Systems, 1997, Atlanta, Georgia.

[11] Clark, L., Health Service Managers Question National Programme Consultation, in Computers Weekly, 2004, London, UK, pp. 6.

[12] Cowan, J., Medication Safety in 2004: the NHS agenda, Clinical Governance: An International Journal (2004), 9(2): pp. 132-135.

[13] DenZIN, N.Y.K., The Research Act: A Theoretical Introduction to Sociological Methods, 1978, McGraw Hill, New York, USA.

[14] Duke, S., P. MAKeY, AND N. KIRAS, Application Integration Management Guide: Strategies and Technologies, 1999, Butler Group Limited: Hull, Yorkshire, UK.

[15] EDWARDS, P. AND R. NEWING, Application Integration for e-Business, 2000, Business Intelligence 2000, London, UK.

[16] EISENHARDT, K.M., Building Theories from Case Study Research, Academy of Management Review (1989), 14(4): pp. 532-550.

[17] FIELD, M.J., Telemedicine: A Guide to Assessing Telecommunications in Health Care, 1996, National Academy Press, Washington, DC, USA.

[18] Flower, J., The End of Health Care as We Know It, in Health Forum Journal, 1999.

[19] GILBERT, M., Importance of magazine Oscar, in Computer Weekly, 2004, London, UK, pp. 30.

[20] Godefridus, G., S. GRoOTHUIS, AND A. HASMAN, Enterprise Resource Planning for Hospitals, International Journal of Medical Informatics (2004), 73(6): pp. 493-501.

[21] Howcroft, D. AND N. MiteV, An empirical study of Internet usage among medical practice management in the UK, Internet Research: Electronic Networking Applications and Policy (2000), 10(2): pp. 170-181.

[22] IRANI, Z., Investment Justification of Information Systems: A Focus on the Evaluation of MRPII, in Department of Manufacturing and Engineering, 1998, Brunel University, London, UK, pp. 250. 
[23] IRANi, Z., M. Themistocleous, AND P.E.D. Love, The Impact of Enterprise Application Integration on Information System Lifecycles, Information and Management (2003), 41(2): pp. 177-187.

[24] JAMES, M., The role of integrated technology solutions in Healthcare reform, in Intelligent Government - The next Wave, S. Willis, Editor, 2002, Cisco Systems, London.

[25] JANESICK, V., The choreography of qualitative research design, in Handbook of qualitative research, N.Y.K. Denzin and Y.S. Lincoln, Editors, 2000, Sage publications: Thousand Oaks, CA, pp. 379399.

[26] KALAKOTA, R. AND M. RoBinson, e-Business: Roadmap for Success, 1999, Addison-Wesley, Boston, Massachusetts, USA, pp. 378.

[27] Khoumbati, K., M. Themistocleous, AND Z. IRANI, A Conceptual Model for the Adoption of Enterprise Application Integration In Healthcare Organizations, in Ninth Americas Conference on Information Systems, (AMCIS 2003), 2003, Tampa, Florida, USA.

[28] Khoumbati, K., M. Themistocleous, AnD Z. IRANI Evaluating Integration Approaches Adopted By Healthcare Organizations, in 12th European Conference on Information Systems, 2004, Turku, Finland.

[29] Khoumbati, K., M. Themistocleous, AND Z. IRANI, Integrating IT Infrastructures in Healthcare Organizations: A Proposition of Influential Factors, Journal of Information Technology and Information Management, 2004, pp. In Press.

[30] Klasell, T. AND S. DudgeOn, Enterprise Application Integration, 1998, Dain Rauscher Wessels, New York, USA, pp. 1-71.

[31] KOHN, L.T. AND J. CORRIGAN, The err is Human: Building a Safer Health System, in National Academic Press, 2000, Washington D.C., USA.

[32] Leape, L., W. BATES, AND J. Cullen, Systems Analysis ofAdverse Drug Events, Journal of American Medical Association (1995), 274(1): pp. 35-43.

[33] LILLYWHITE, T.P., Implementing BS7799 in the UK National Health Service, Computer Fraud \& Security (2004), 2004(2): pp. 4-8.

[34] LinTHICUM, D., Enterprise Application Integration, first ed. 1999, Addison-Wesley, Massachusetts, USA, pp. 377.

[35] LINTHICUM, D., Enterprise Application Integration from the Ground Up, 1999, Software Development Magazine.

[36] LINTHICUM, D., B2B Application Integration, first ed. 2000, Addison-Wesley, Massachusetts, USA, pp. 408.

[37] LUBINSKI, D. AND S. BARR, Helathcare without boundaries: Integration Technology for the new healthcare economy, M. Corp., Editor, 2003, USA.
[38] MARTIN, M., An ERP Strategy, in Fortune, 1998, pp. 95-97.

[39] Martinez, J. AND Y. Redondo, Key Variables in the EDI Adoption by Retail Firms, Technovation (2001), 21(3): pp. 385-394.

[40] Miles, M.B. AND A.M. Huberman, Qualitative Data Analysis: An Expanded Sourcebook, 1994, Sage publications, Newbury Park, California, USA.

[41] Missi, F., S. Alshawi, AND G. Fitzerald, Towards a Framework for Realizing Healthcare Management Benefits Through The Integration of Patient's Information, in 12th European Conference on Information Systems, 2004, Turku, Finland.

[42] Motsios, T., Implementing ERP systems, 1999, Athens University of Economics and Business, Athens, pp. 162.

[43] Murray, M., An Investigation of Specifications for Migrating to a Web Portal Framework for the Dissemination of Health Information within a Public Health Network, in 35th Hawaii International Conference on System Sciences, 2002, Big Island, Hawaii, USA: IEEE Computer Society, Los Alamitos, California, USA.

[44] Ragupathi, W., Health Care Informaton Systems, Communications of the ACM (1997), 40(8): pp. 81-82.

[45] RING, K. AND N. WARD-DuTTON, Enterprise Application Integration: Making the Right Connections, first ed. 1999, Ovum Ltd, London, UK, pp. 276.

[46] RuH, W., F. Maginnis, AND W. BROWn, Enterprise Application Integration: A Wiley Tech Brief, 2000, Wiley John Wiley \& Sons Inc., New York, USA.

[47] SELBY, S., A policy framework for commissioning cancer services, 1995.

[48] Sutherland, J. AND J. WiLlem, Enterprise Application Integration and Complex Adaptive Systems, Communications of the ACM (2002), 45(10): pp. 59-64.

[49] TAi, S., C. Donegan, AND I. NAZARETh, Computers in General Practice and the consultation: the health professionals view, Health Informatics Journal (2000), 6: pp. 27-31.

[50] Themistocleous, M., Evaluating the Adoption of Enterprise Application Integration in Multinational Organizations, in Department of Information Systems and Computing, 2002, Brunel University, London.

[51] Themistocleous, M., Justifying the Decision for EAI Implementations: A Validated Proposition of Factors, Journal of Enterprise Information Management (2004), 17(2): pp. 85-104.

[52] Themistocleous, M. AND Z. IRANI, Benchmarking the Benefits and Barriers of Application Integration, Benchmarking: An International Journal (2001), 8(4): pp. 317-331. 
[53] Themistocleous, M., ET AL., Extending the Information System Lifecycle through Enterprise Application Integration: A Case Study Experience, in Thirty-Seventh Annual Hawaii International Conference on System Sciences, (Hicss 37), 2004, Big Island, Hawaii, USA: IEEE Computer Society, Los Alamitos, California, USA.

[54] Themistocleous, M., Z. IRANI, AND P.E.D. LOVE, Evaluating the Integration of Supply Chain Information Systems: A Case Study, European Journal of Operational Research (2004), 159(2): pp. 393405.

[55] Themistocleous, M., Z. IRANI, AND A. Sharif, Evaluating Application Integration, in seventh European Conference on Evaluation of Information Technology (ECITE 2000), 2000, Dublin, Ireland: MCIL Reading, UK.

[56] URLOCKER, Z., Return to eBusiness Integration, in EAI Journal, 2000.

[57] WANLESS, D., Securing our Future Health: Taking a Long-Term View, 2002, London, pp. 137-164.

[58] ZAHAVI, R., Enterprise Application Integration with CORBA, First ed. 1999, John Wiley and Sons Inc., New York, USA, pp. 498.

[59] Zhanjun, C., Realization of integration and working procedure on digital hospital information system. Computer Standards \& Interfaces (2003), 22(6): pp. 1-9.

Received: July 2004 Revised: August 2004 Accepted: August 2004

Contact address

Marinos Themistocleous Information Systems Evaluation and Integration Network Group (ISEing)

Department of Information Systems and Computing Brunel University Uxbridge Middlesex UB8 3PH UK

e-mail: Marinos.Themistocleous@brunel.ac.uk

VASILIKI MANTZANA is a PhD student at the Department of Information Systems and Computing, Brunel University, UK. Her research focuses on the integration of healthcare information systems.

MARINOS THEMISTOCLEOUS is a Lecturer at the Department of Information Systems and Computing, Brunel University, UK. His research interests are around the Enterprise Application Integration technology and the Enterprise Systems. 